\title{
Design and Analysis of the W7-X Divertor Scraper Element
}

\author{
A. Lumsdaine ${ }^{\mathrm{a}}$, J. Tipton ${ }^{\mathrm{b}}$, J. Lore ${ }^{\mathrm{a}}$, D. McGinnis ${ }^{\mathrm{a}}, \mathrm{J}_{\text {. Canik }}^{\mathrm{a}}$, J. Harris ${ }^{\mathrm{a}}$, A. Peacock ${ }^{\mathrm{c}}, \mathrm{J}$. Boscary ${ }^{\mathrm{c}}$, J. \\ Tretter $^{\mathrm{c}}$, T. Andreeva ${ }^{\mathrm{d}}$ \\ ${ }^{a}$ Oak Ridge National Lab, Oak Ridge, TN, USA \\ ${ }^{b}$ University of Evansville, Evansville, IN, USA \\ ${ }^{c}$ Max Planck Institute for Plasma Physics, Garching, Germany \\ ${ }^{d}$ Max Planck Institute for Plasma Physics, Greifswald, Germany
}

The high heat-flux divertor of the Wendelstein 7-X large stellarator experiment consists of 10 divertor units which are designed to carry a steady-state heat flux of $10 \mathrm{MW} / \mathrm{m}^{2}$. However, the edge elements of this divertor are limited to only $5 \mathrm{MW} / \mathrm{m}^{2}$, and may be overloaded in certain plasma scenarios. It is proposed to reduce this heat by placing an additional "scraper element" in each of the ten divertor locations. It will be constructed using carbon fiber composite (CFC) monoblock technology. The design of the monoblocks and the path of the cooling tubes must be optimized in order to survive the significant steady-state heat loads, provide adequate coverage for the existing divertor, be located within sub-millimeter accuracy, and take into account the boundaries to other in vessel components, all at a minimum cost. Computational fluid dynamics modeling has been performed to examine the thermal transfer through the monoblock swirl tube channels for the design of the monoblock orientation. An iterative physics modeling and computer aided design process is being performed to optimize the placement of the scraper element within the severe spatial restrictions.

Keywords: divertor; high heat flux; stellarator; computational fluid dynamics; plasma facing components

\section{Introduction}

\subsection{Background}

The Wendelstein 7-X large stellarator experiment is planned for completion in 2014 and starting plasma operation in 2015. For the first years of plasma operation, the device will use an inertially cooled divertor, which limits the plasma pulse time to approximately 10 seconds [1]. This will be replaced with a high-heat flux divertor that is water-cooled. In the high heat flux phase of operation, the stellarator will increase its pulse length to 30 minutes and allow for steady-state plasma fluxes. The high heat-flux divertor consists of 10 divertor units. The target elements of each divertor unit (see Fig. 1) are designed to carry a steadystate heat flux of $10 \mathrm{MW} / \mathrm{m}^{2}$. However, the edge elements of these target plates are limited to only 5 $\mathrm{MW} / \mathrm{m}^{2}$ [2]. In certain plasma scenarios during this high-heat-flux phase of operation, a bootstrap current develops in the plasma, causing the edge elements to receive heat fluxes beyond this limit [3]. It is proposed to reduce this heat by placing an additional "scraper element" (SE) in each of the ten divertor locations.

The SE will experience up to a $400 \mathrm{~kW}$, steady-state, mostly convective heat load, with localized loads as high as $12 \mathrm{MW} / \mathrm{m}^{2}$ in the initial design concept. It will be constructed using carbon fiber composite (CFC) watercooled monoblock technology, and placed within an extremely limited operational space. The design of the monoblocks and the path of the cooling tubes must be optimized in order to survive the significant steady-state heat loads, provide adequate coverage for the existing divertor, be located within sub-millimeter accuracy, and take into account the boundaries to other in-vessel components, all at a minimum cost.

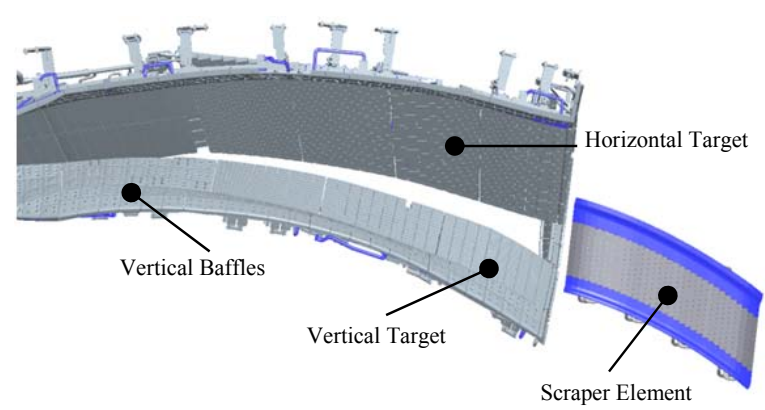

Fig.1 Components of a divertor unit with scraper element concept.

\subsection{Problem Statement}

The design requirements on the SE that are pertinent to the current analysis may be stated as:

- The pressure drop in cooling water should be less than $1.4 \mathrm{MPa}$.

- The maximum temperature of the CFC surface should remain under $1200{ }^{\circ} \mathrm{C}$.

- The bulk water temperature should not rise above 80 ${ }^{\circ} \mathrm{C}\left(50{ }^{\circ} \mathrm{C}\right.$ increase).

- The heat load on the end of the divertor target element must be reduced to less than $5 \mathrm{MW} / \mathrm{m}^{2}$.

- The maximum localized heat load on the SE should be maintained below $12 \mathrm{MW} / \mathrm{m}^{2}$. 
Monoblock technology is chosen for the SE design, as it is a validated technology for high heat flux components and has been qualified to be capable of surviving steady state heat loads up to $20 \mathrm{MW} / \mathrm{m}^{2}$ [4]. A key question in the design of the $\mathrm{SE}$ is whether the cooling pipes of the monoblocks should be oriented poloidally or toroidally. Fig. 2 shows a schematic (from a top view) of poloidal and toroidal SE concepts. First, an analysis is performed to examine which of these orientations is preferred. Second, software is developed to calculate the convective heat loads on the divertor components. Using this code, the SE surface is designed iteratively as a compromise between satisfying heat load design criteria and fitting the SE in the limited design space (as determined by the CAD model).

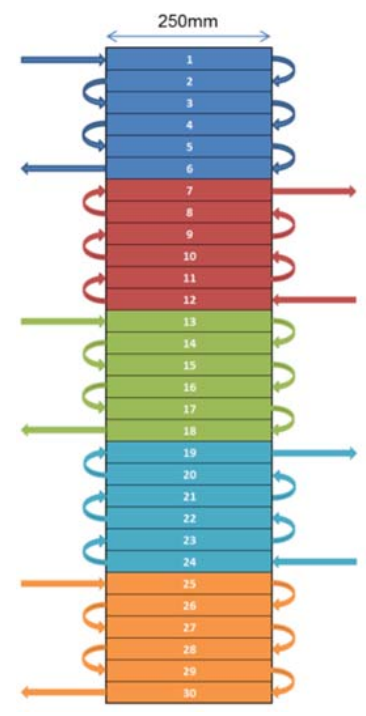

(a)

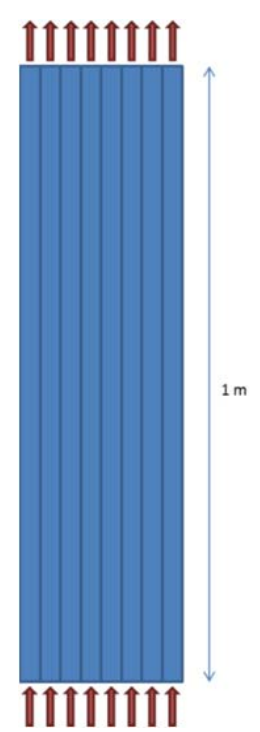

(b)
Fig.2 Schematic of (a) poloidally oriented and (b) toroidally oriented SE

\section{Scraper Element Orientation}

\subsection{Pressure Drop Calculation}

The cross-section of the type of monoblock that is planned for the W7-X SE is shown below in Fig. 3(b). The monoblock is made of an orthotropic carbon-carbon fiber composite (CFC) with an internal copper tube for water cooling. The CFC is bonded to a copper substrate, which in turn is bonded to a $\mathrm{CuCrZr}$ alloy. A twisted tape is inserted into the tube in order to increase fluid mixing and prevent critical heat flux (CHF) conditions. The twist ratio is 2 and the thickness is $1 \mathrm{~mm}$. The SE geometry is simplified as a flat, rectangular system, as shown in Fig. 2, for the sake of the analysis presented.

For a tube with a twisted tape insert, according to the correlations developed by Manglik and Bergles for turbulent flow [5] the pressure drop may be calculated:

$$
\Delta p=f \frac{l}{D} \frac{\rho u_{m}^{2}}{2}
$$

where the friction factor is calculated using:

$$
\begin{gathered}
f=\frac{0.0791}{R e^{0.25}}\left[\frac{\pi}{\pi-4(\delta / D)}\right]^{1.75}\left[\frac{\pi+2-2(\delta / D)}{\pi-4(\delta / D)}\right]^{1.25} \\
{\left[1+\frac{2.752}{y^{1.29}}\right]\left(\frac{\mu_{\text {bulk }}}{\mu_{\text {wall }}}\right)^{-0.25}}
\end{gathered}
$$

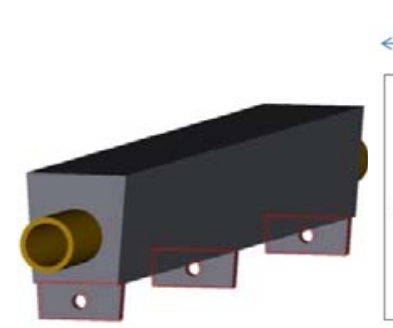

(a)

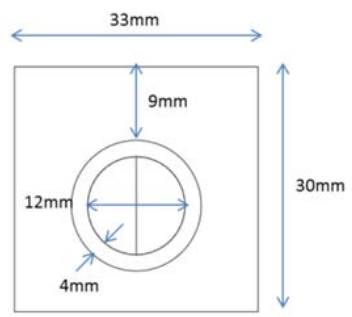

(b)
Fig.3 Monoblock design (a) 3D view of single monoblock finger concept; (b) cross-section used in analysis.

The pressure drop of a 180 degree pipe bend (with no twisted tape insert) is calculated using [6]. Assuming 30 monoblock fingers for the poloidal case, and 8 monoblock fingers for the toroidal case (as shown in Fig. 2), the total pressure drop is calculated versus the number of parallel fluid passes (shown in Table 1). For the toroidal case, one long pass through all 8 rows of monoblocks results in an extremely high pressure drop $(68.4 \mathrm{MPa})$ and so is not feasible for design. In fact, even four separate passes results in a pressure drop (1.5 $\mathrm{MPa})$ that violates the requirement of $1.4 \mathrm{MPa}$. So, a toroidal orientation requires 8 separate passes. For the poloidal case, a minimum of 5 parallel fluid passes are required which is shown in Fig. 2(a).

Table 1: Pressure drop (in MPa)

\begin{tabular}{lccccccc}
\hline \# of passes & 1 & 2 & 3 & 4 & 5 & 6 & 8 \\
\hline Toroidal & 68.4 & 10.1 & - & 1.5 & - & - & 0.21 \\
Poloidal & 75.0 & - & 3.5 & - & 0.85 & 0.51 & -
\end{tabular}

\subsection{Thermal/Computational Modeling}

An analysis of a monoblock design, including a computational fluid dynamics (CFD) simulation of flow through the monoblock tubes with twisted tape was conducted in order to verify that the primary thermalfluid design criteria could be met. Checking the other two thermal requirements (peak CFC temperature and water temperature rise) requires assuming a heat load and water flow rate. The latter value can be calculated by simple energy balance, and the former with the aid of the ANSYS ${ }^{\circledR}$ CFX software. The water flow rate is calculated assuming a $30 \mathrm{~mm}$ inlet pipe with water flowing at $10 \mathrm{~m} / \mathrm{s}$ at $30{ }^{\circ} \mathrm{C}$. To a first approximation, the heat load can be approximated as a $12 \mathrm{MW} / \mathrm{m}^{2}$ local flux applied over $\sim 13 \%$ of the surface area to equal $400 \mathrm{~kW}$ 
total power input. The following assumptions are included in the analysis:

- Steady-state

- K- $\varepsilon$ turbulence model with semi-empirical near-wall effects

- No radiation heat transfer

- Adiabatic CFC walls

- $\quad$ Pipe is entirely $\mathrm{CuCrZr}$

- No heat transfer in pipe bends

- Pipe bends replaced with grid connections

- Twisted tape modeled as thin surface

- $1 \mathrm{D}$ heat transfer through thickness of twisted tape

For the poloidal case, a SE with five parallel flow circuits, each consisting of six channel passes in the poloidal direction, was modeled. Given the total heat load of $400 \mathrm{~kW}$ and total mass flow rate of $7.187 \mathrm{~kg} / \mathrm{s}$, a simple energy balance gives the mean outlet water temperature as $43{ }^{\circ} \mathrm{C}$ (increase of $13{ }^{\circ} \mathrm{C}$ ). For the toroidal case, where eight parallel flow circuits were modeled, the entire heat load may be carried by a single monoblock finger. In this case, energy balance gives the mean outlet water temperature on a single tube as $137^{\circ} \mathrm{C}$ (increase of $107^{\circ} \mathrm{C}$ ), which is a violation of the design requirement. If a single monoblock finger carries only half of the heat load, then the mean outlet temperature for each tube is $84{ }^{\circ} \mathrm{C}$ (increase of $54{ }^{\circ} \mathrm{C}$ ), which is a slight violation of the design requirement.

The maximum temperature in the CFC calculated from the CFD simulation is shown below in Table 2 . Note that, for the toroidal case, it is assumed that all (middle row) or half (bottom row) of the heat load is carried by a single monoblock row. Fig. 4 shows the temperature of the top surface of the monoblocks for the poloidal case. It can be seen that, in the toroidally oriented case, if the entire heat load is carried by a single monoblock finger, the CFC peak temperature rises above $1200{ }^{\circ} \mathrm{C}$, which is a violation of one of the design criteria. If the heat is shared evenly between two monoblock fingers, the peak CFC temperature is below this threshold, but the poloidal case gives a greater margin.

Table 2: Results from CFD Analysis

\begin{tabular}{lccccc}
\hline & $\begin{array}{c}\mathrm{m} \\
(\mathrm{kg} / \mathrm{s})\end{array}$ & $\begin{array}{c}\text { Heat } \\
(\mathrm{MW} / \\
\left.\mathrm{m}^{2}\right)\end{array}$ & $\begin{array}{c}\text { Mean } \\
\text { Water } \\
\text { Temp } \\
\left({ }^{\circ} \mathrm{C}\right)\end{array}$ & $\begin{array}{c}\text { Peak } \\
\text { Water } \\
\text { Temp } \\
\left({ }^{\circ} \mathrm{C}\right)\end{array}$ & $\begin{array}{c}\text { Peak } \\
\mathrm{CFC} \\
\text { Temp } \\
\left({ }^{\circ} \mathrm{C}\right)\end{array}$ \\
\hline Poloidal & 1.44 & 12 & 43.0 & & 976 \\
Toroidal & 0.89 & 12 & 137.4 & 176 & 1277 \\
Toroidal & 0.89 & 6 & 83.7 & 105 & 1081
\end{tabular}

The poloidally oriented monoblock was chosen for the SE design for the following reasons:

- Analysis indicated that the poloidally oriented monoblocks could better handle the heat load.

- The SE surface will need to be curved toroidally. The experience of the monoblock manufacturer in the frame of the R\&D activities shows that it has the capability of including curvature, but the amount of curvature with an internal twisted tape is limited.

- The manufacturer had limited experience with making rows of monoblocks of this length $(1 \mathrm{~m})$ and had concerns about being able to maintain quality.

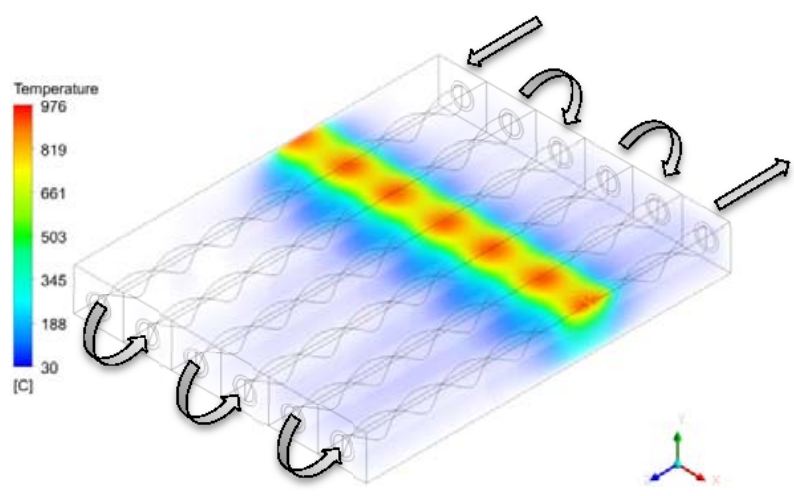

Fig.4 Temperature of SE from CFD result.

\section{Design Process}

\subsection{Heat Load Calculation}

The heat flux to the divertor elements is calculated using the field line diffusion code DIV3D developed at ORNL. The details of the development and implementation of this code are given in [7]. Fig. 5 shows strike points (where field lines intersect with the target plates) and the resulting heat fluxes for the critical plasma configuration (where the evolving bootstrap current results in the high heat flux on the edges of the divertor targets). It is seen in the top picture in Fig. 5 that the edge of the horizontal target reaches a heat flux of over $10 \mathrm{MW} / \mathrm{m}^{2}$ (where the design criteria requires that it remain under $5 \mathrm{MW} / \mathrm{m}^{2}$ ). The bottom picture in Fig. 5 shows the same plasma case with the inclusion of the SE, which reduces the heat load on the horizontal target edges to less than $3 \mathrm{MW} / \mathrm{m}^{2}$. The peak heat flux on the SE is slightly over $12 \mathrm{MW} / \mathrm{m}^{2}$ in this case, but the SE contour is not fully optimized, and further manipulation in the surface shape has shown that this can be reduced to less than $10 \mathrm{MW} / \mathrm{m}^{2}$.

\subsection{Design Considerations}

In order to allow space for automated welding of pipe joints using an orbital welder, a design concept was developed involving interleaving monoblock modules as shown in Fig. 6. Graphite covers must then be placed over these exposed pipes in order to protect them from both radiative and convective heat fluxes. Because of the severe space limitations and $3 \mathrm{D}$ nature of the stellarator, iteration is required between the SE surface developed from the heat flux simulation, and the positioning of the SE (with piping) in the CAD model. Fig. 7 shows the extremely tight clearance between the SE piping and the actively cooled plating which protects the plasma vessel. Continued iteration is required to develop a SE surface that meets all of the design criteria and fits into the very limited space available. 

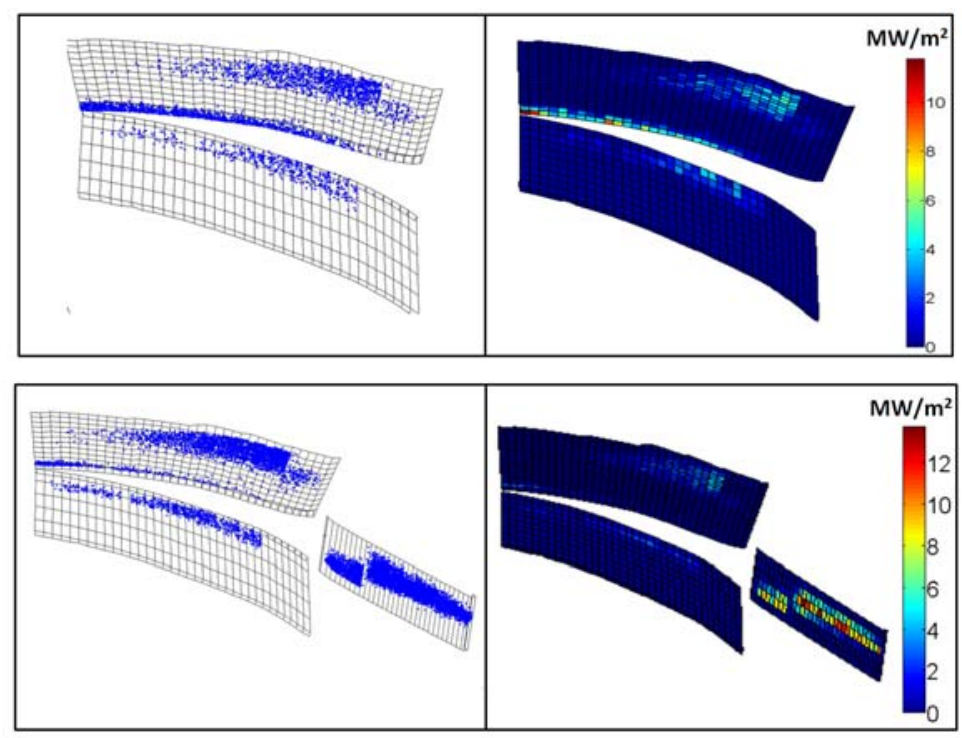

Fig.5 Strike points (left) and heat fluxes (right) onto the primary targets and SE in the bootstrap current configuration without (top) and with (bottom) the SE.

\section{Further Study}

The following issues need to be considered for the development of the SE final design:

- Further analysis using the actual calculated heat loads needs to be completed to estimate the margin to critical heat flux conditions. A combination of CFD simulations and empirical data will be used for this estimation.

- The effect of the SE on neutral particle transport should be evaluated using a 3D transport code such as EMC3-EIRENE [8].

- A thermal stress analysis will be completed to ensure the integrity of the SE and supports.

- Further analysis to optimize the size of the SE with respect to the input power and maximum incident heat flux to reduce the costs and obtain more space for the cooling system.
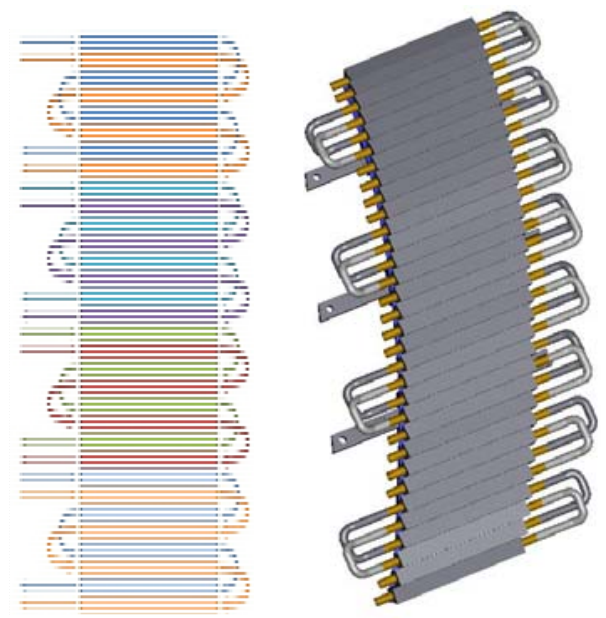

Fig.6 Schematic (left) and actual (right) SE piping designs.

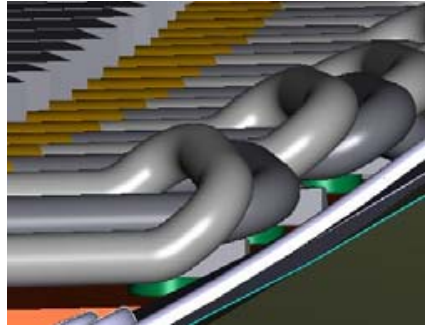

Fig.7 Only $10 \mathrm{~mm}$ of clearance available in this concept of piping design.

\section{Acknowledgments}

This work is supported in part by US DOE Contract Number DE-AC05-00OR22725

\section{References}

[1] H. S. Bosch et al., Contr. Plasma Phys., 687, 50, 8, (2010).

[2] J. Boscary et al., Fus. Eng. Des., 87, 1453 (2012).

[3] J. Geiger et al., $23^{\text {rd }}$ IAEA Fus. Energy Conf. THC-P 2-02 (2010).

[4] M. Richou et al., Phys. Scr. T145, (2011).

[5] R.M.. Manglik and A.E. Bergles, J. Heat Transfer, 890-896 115, (1993).

[6] Crane Flow of Fluids, TP-410 (2009).

[7] J.D. Lore, et al, to be published in the proceedings of the IAEA Fus. Energy Conf., (2012).

[8] Y. Feng, et al, J. Nucl. Mater. 266-269, 812 (1999). 